\title{
Changes in lipid composition and lipid peroxidation products content in the freshwater mussel Anodonta cygnea L. under cadmium effect
}

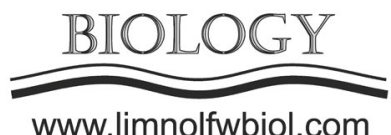

www.limnolfwbiol.com

\author{
Fokina N.N.*, Vasil'eva O.B., Ruokolainen T.R., Nemova N.N. \\ Institute of Biology of Karelian Research Centre of Russian Academy of Sciences, Pushkinskaja St. 11, 185910 Petrozavodsk, Russia
}

\begin{abstract}
In order to identify specific biomarkers to cadmium-induced oxidative stress in freshwater organisms, changes in the composition of membrane and storage lipids and their fatty acids in the gills and digestive glands of freshwater mussels, Anodonta cygnea (Linnaeus, 1758), exposed to cadmium ions at 10, 50 and $100 \mu \mathrm{g} / \mathrm{L}$ were studied. Cadmium-induced oxidative stress was estimated by the content of lipid peroxidation products such as conjugated dienes and trienes, malondialdehyde, and Schiff bases. Accumulation of lipid peroxidation products in the gills and digestive glands reflected the intensity of lipid peroxidation, depending on the concentration and duration of cadmium exposure. Changes in the fatty acid composition of phospholipids and triacylglycerols reflected their compensatory role in the response of the mussels to the action of cadmium at various concentrations. Some indices of lipid composition (phosphatidylserine and triacylglycerol content) similarly altered under cadmium effect in both marine and freshwater mussels. The assessment of oxidative stress biomarkers and the main targets for these oxidative processes including lipids and their fatty acid composition makes it possible to identify protective biochemical mechanisms providing the high resistance of mussels to environmental pollution.
\end{abstract}

Keywords: phospholipids, fatty acids, malondialdehyde, metal, toxicity, bivalves

\section{Introduction}

Mussels are used as sentinel organisms in monitoring studies of aquatic ecosystems, as well as in ecological and toxicological studies of the effects of metal accumulation on the health of organisms (Perceval et al., 2002; Wadige et al., 2014). Assessment of cadmium effects on the vitality of organisms exists for both marine and freshwater mussels (Geret et al., 2002; Perceval et al., 2002; Wadige et al., 2014). A wide range of the mussels responses to cadmium has been shown: enzyme inhibition and injury to cell membranes (Chelomin et al., 1998), apoptosis induction (Xia et al., 2016), and neurotoxicity (Méndez-Armenta and Ríos, 2007). Metals with variable oxidation states may disrupt biological membrane composition, initiating lipid peroxidation (LPO) by Fenton reactions (Valko et al., 2005; Oxidative stress..., 2011). Cadmium ions and their chelate complexes cannot take part in the formation of reactive oxygen species through such redox processes but suppress the activity of antioxidant enzymes, provoking the unregulated formation of reactive oxygen species and eventually inducing peroxidation of polyunsaturated fatty acids in membrane phospholipids (Viarengo et al., 1990; Regoli et al., 1998; Geret et al., 2002; Valko et al., 2005; Oxidative stress..., 2011; Repetto et al., 2012). In ecological and toxicological studies, to assess the intensity of LPO, the concentration of malondialdehyde (MDA) is used as a marker of oxidative stress (e.g., Oxidative stress..., 2011). LPO is accompanied by the formation of a wide range of intermediate products possessing toxic effects on the organism and damaging the composition of lipoproteins, proteins and nucleic acids (Waller and Recknagel, 1977). The composition of the intermediate LPO products is determined by the membrane lipid composition exposed to oxidative stress ( Sevanian and Hochstein, 1985; Gutteridge and Halliwell, 1990). Thus, conjugated dienes (CoD) are the primary LPO products of polyunsaturated fatty acids (PUFA) and contain 3 or more double bonds (termed highly unsaturated fatty acids, HUFA). MDA is a common product of the lipid hydroperoxide decomposition of HUFA. Conjugated trienes (CoT) are formed from $\mathrm{CoD}$ and possess stronger cytotoxic effects than diene conjugates (Suzuki et al., 2001). The product of the interaction of MDA and the amino groups of phospholipids and proteins are Schiff bases (SchB). SchB constitutes molecular crosslinks with membrane components (mainly proteins) disrupting in cell membranes (Traverso et al., 2004).

Changes in lipid composition of mussels have been shown as an effect of cadmium exposure (Fokina et al., 2013; Merad et al., 2017). Along with LPO products, lipid and fatty acid composition can serve as biomarkers reflecting the toxic 
effects of metals on organism health status (Gladyshev et al., 2012; Fokina et al., 2013; Perrat et al., 2013; Merad et al., 2017). For example, the accumulation of neutral lipids, including triacylglycerols, in the digestive glands of mussels is a biomarker for environmental contamination, and it indicates the activation of autophagy processes (Moore et al., 2007). However, the regulation of lipid composition seems to be a compensatory mechanism to prevent non-selective membrane permeability to ions by the adverse effects of oxidative stress (Gladyshev et al., 2012; Fokina et al., 2013). In particular, increases in cholesterol and oleic acid contents, which probably contribute to the stabilization of membrane permeability and metal detoxification under the impact of copper, were shown in the marine mussels, Mytilus edulis L. (Fokina et al., 2013). In the studies of the metal-induced oxidative stress effects on organism health, it is recommended to evaluate not only changes in LPO products but also changes in its substrates, i.e., in lipid and fatty acid composition. Thus, the study of the lipid and fatty acid composition (triacylglycerols, sterols and phospholipid fractions) and LPO products (conjugated dienes and trienes, malondialdehyde and Schiff bases) in the gills and digestive glands of freshwater mussels, Anodonta cygnea (Linnaeus, 1758), is required to identify the biomarkers reflecting the cadmium effect.

\section{Materials and methods 2.1. Experiment design}

Adult freshwater mussels, Anodonta cygnea (Linnaeus, 1758), were collected from the Suna River (Republic of Karelia, Russia). The mussel samples were taken from a riverbed historically isolated from sources of industrial pollution. Our results of the whole body mussel tissues analysis by inductively coupled plasma mass spectrometry (XSeries-2 ICP-MS, Thermo Fisher Scientific, Waltham, MA, USA) showed that cadmium content in the mussels was $0.9 \mathrm{mg} / \mathrm{kg}$. In particular, it was shown that mussels from urban localities contain 3.9 to $4.6 \mathrm{mg} / \mathrm{kg}$ cadmium compared to mussels from rural areas, which contain $0.4-3.2 \mathrm{mg} / \mathrm{kg}$ of cadmium (Manly and George, 1977). Shell length was $71.7 \pm 3.8 \mathrm{~mm}$. Total weight of mussels (soft tissues + mantle fluid+shell) was $34.5 \pm 5.9 \mathrm{~g}$. The experiments were conducted at the Aquarium Complex of the Institute. The mussels were acclimated to laboratory conditions for seven days in 5 L Plexiglas ${ }^{\circledR}$ aquariums containing dechlorinated water, with a 12/12 photoperiod and constant aeration (4 mussels per aquarium). The physical and chemical parameters of the aquarium water were monitored. The temperature was $22 \pm 1.0{ }^{\circ} \mathrm{C}, \mathrm{pH}=7.4 \pm 0.03$, dissolved oxygen (DO) $8.3 \pm$ $0.5 \mathrm{mg} / \mathrm{L}$, total mineralisation $11.8 \pm 1.6 \mathrm{mg} / \mathrm{L}$, total water hardness $0.5-0.85 \mathrm{mmol} / \mathrm{L}, \mathrm{NH}_{4}^{+} 1.5 \pm 0.5 \mathrm{mg} / \mathrm{L}, \mathrm{NO}_{2}^{-} 0.0$ $\mathrm{mg} / \mathrm{L}, \mathrm{NO}_{3}{ }^{-} 1.2 \pm 1.2 \mathrm{mg} / \mathrm{L}, \mathrm{SO}_{4}{ }^{2-} 14.2 \pm 0.3 \mathrm{mg} / \mathrm{L}$, and $\mathrm{Cl}^{-} 3.2$ $\pm 0.9 \mathrm{mg} / \mathrm{L}$. The water was replaced twice a day.

After acclimation, the mussels were divided into eight groups of 4 mussels each: the control was exposed to dechlorinated water (two aquariums), and three experimental groups were exposed to 10,50 , and $100 \mu \mathrm{g} / \mathrm{L}$ of cadmium (two aquariums for each experimental group). A stock solution of cadmium was prepared by dissolving cadmium (II) chloride in distilled water to a $\mathrm{Cd}^{2+}$ concentration of 20 $\mathrm{mg} / \mathrm{L}$. The aquarium water was renewed twice a day and further the calculated amount of cadmium stock solution was added in aquarium water after each water change. During the experiment, the water temperature, $\mathrm{pH}, \mathrm{DO}$, total mineralisation, total water hardness and anion content were monitored and kept stable (means $\pm \mathrm{SD}$ ): $21 \pm 1.0{ }^{\circ} \mathrm{C}, 7.0$ $\pm 0.1,7.8 \pm 0.5 \mathrm{mg} / \mathrm{L}, 11.8 \pm 1.4 \mathrm{mg} / \mathrm{L}, 0.5-0.85 \mathrm{mmol} / \mathrm{L}$, $\mathrm{NH}_{4}^{+} 1.7 \pm 0.4 \mathrm{mg} / \mathrm{L}, \mathrm{NO}_{2}^{-} 0.09 \pm 0.03 \mathrm{mg} / \mathrm{L}, \mathrm{NO}_{3}^{-} 2.5 \pm 0.0$ $\mathrm{mg} / \mathrm{L}, \mathrm{SO}_{4}^{2-} 14.2 \pm 0.5 \mathrm{mg} / \mathrm{L}$, and $\mathrm{Cl}^{-} 4.2 \pm 0.4 \mathrm{mg} / \mathrm{L}$. After every 24-hour experimental exposure of mussels, aquarium water was taken to analyze its cation composition (Fig. 1) by inductively coupled plasma mass spectrometry (XSeries-2 ICP-MS, Thermo Fisher Scientific, Waltham, MA, USA) (Slukovskii et al., 2017).

At the end of the experiment (one and three days), the soft tissues of $A$. cygnea (gills and digestive glands, $\mathrm{n}=4$, from each experimental treatment group) were fixed for further biochemical analysis. Until the lipid analysis, the tissues were stored in $96 \%$ ethanol at $4{ }^{\circ} \mathrm{C}$. Tissues for lipid peroxidation products and cation composition measurements were stored at $-80{ }^{\circ} \mathrm{C}$. Frozen soft tissues for cation composition were freeze dried for 24 hours (FreeZone, Labconco, Kansas City, MO, USA) and analyzed by ICP-MS.

\subsection{Biochemical analysis}

Biochemical analyses of the lipid peroxidation products and the lipid profiles in the gills and digestive glands of the freshwater mussels, A. cygnea, were conducted in the Equipment Sharing Centre of the Karelian Research Centre of the Russian Academy of Sciences (Petrozavodsk, Russia).

Analysis of total lipid composition

Lipids were extracted with chloroform/methanol (2:1, $\mathrm{v} / \mathrm{v}$ ) according to Folch et al. (1957). The extracted lipids were spotted onto silica gel thin-layer chromatography plates (TLC Silica gel 60 F254 plates, "Merck", Germany) and separated into different fractions of lipid classes using petroleum ether/ diethyl ether/acetic acid (90:10:1, v/v) as the mobile phase. The identification of the fractions was performed using standards: phospholipid mixture (P3817 "Supelco", USA), cholesterol (C8667 "Sigma", USA), glyceryl trioleate (92860 "Sigma", USA) and cholesteryl palmitate (C78607 "Aldrich", USA). The quantitative composition of the fractions was measured at $540 \mathrm{~nm}$ wavelength for phospholipids, triacylglycerols and sterol esters and $550 \mathrm{~nm}$ wavelength for the sterol fraction using an SF-2000 UV/Vis spectrophotometer (SaintPetersburg, Russia) (Sidorov et al., 1972; Engelbrecht et al., 1974).

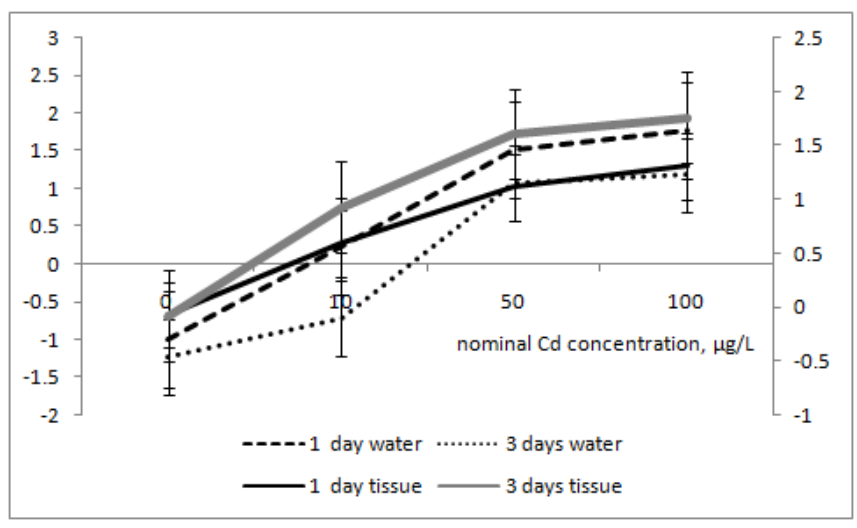

Fig. 1. Cadmium concentration (log10-transformed) in aquarium water $(\mu \mathrm{g} / \mathrm{L})$ and mussel tissues $(\mu \mathrm{g} / \mathrm{g}$ dry weight). 


\section{Phospholipid fractions determination}

The composition of phospholipid fractions (phosphatidylinositol (PI), phosphatidylserine (PS), phosphatidylethanolamine (PE), phosphatidylcholine (PC), lysophosphatidylcholine (LPC) and sphingomyelin (SM)) was determined by high-performance liquid chromatography using the method of Arduini et al. (1996) on a Nucleosil 100-7 column ("Elsiko", Russia) with the liquid phase acetonitrile/ hexane/methanol/phosphorus acid (918:30:30:17.5, v/v) and UV-spectrophotometer at a $206 \mathrm{~nm}$ wavelength using liquid chromatography from "Aquilon. Stayer" (Moscow, Russia). Peaks were identified by reference to the retention times of the authentic standards: phospholipid mixture (P3817 "Supelco", USA), phosphatidylserine (P7769, "Sigma", USA) and sphingomyelin (S7004, "Sigma", USA).

Analysis of fatty acid composition in phospholipids and triacylglycerols

The total phospholipids and triacylglycerols fractions were separated from the total lipids using thin-layer chromatography on TLC Silica gel 60 F254 plates ("Merck", Germany). Fatty acid methyl esters (FAME) from the fractions were prepared using methanol and acetyl chloride. The separation of FAME was in an "Agilent 7890A" gas-liquid chromatograph ("Agilent Technologies", USA) with a flame ionization detector using "DB-23" columns $(60 \mathrm{~m}-0.25 \mathrm{~mm})$ ("Agilent Technologies", USA) and nitrogen as the mobile phase. FAMEs were identified by comparison with standard mixes ("Supelco", USA). The degree of unsaturation of the phospholipids and triacylglycerols was estimated using an unsaturation index (UI), which was calculated as UI $=(\%$ monoenoic $\mathrm{FA}+2 \cdot \%$ dienoic $\mathrm{FA}+3 \cdot \%$ trienoicFA + $4 \bullet \%$ tetraenoicFA $+5 \cdot \%$ pentaenoicFA $+6 \bullet \%$ hexaenoicFA)/ $\Sigma$ saturated FA (Pirini et al., 2007).

Analysis of lipid peroxidation products

Conjugated dienes (CoD) were analysed in lipid extract prepared by Folch et al. (1957) method. An aliquot of the lipid extract was redissolved in a methanol/pentane mixture $(5: 1, \mathrm{v} / \mathrm{v})$ and was measured at $233 \mathrm{~nm}\left(\varepsilon=2.1 \times 10^{4} \mathrm{M}^{-1} \mathrm{~cm}^{-1}\right)$. $\mathrm{CoD}$ level was expressed in $\mathrm{nmol} / \mathrm{g}$ of wet tissue (Gavrilov et al., 1987). Malondialdehyde (MDA) was measured by the thiobarbituric acid reactive species method (Ohkawa et al., 1979; Bird and Draper, 1984) by adding of $0.2 \mathrm{~mL}$ of tissue homogenate to $1.5 \mathrm{~mL}$ of $20 \%$ orthophosphoric acid (pH 3.5 ) and $1.5 \mathrm{~mL}$ of $0.8 \%$ thiobarbituric acid. Then, samples were heated in a $95{ }^{\circ} \mathrm{C}$ water bath for $1 \mathrm{~h}$. After cooling, $1.0 \mathrm{~mL}$ chilled water and $5.0 \mathrm{~mL}$ butanol-pyridine mixture $(15: 1, v / v)$ were added. Samples were vortexed for $15 \mathrm{~s}$. The flocculent precipitate was removed by centrifugation at 3000 $\mathrm{g}$ for $10 \mathrm{~min}$. Homogenate absorbance was measured at 532 $\mathrm{nm}$ using 1,1,3,3-tetra-ethoxy-propane as a reference. The MDA level was expressed in $\mathrm{nmol} / \mathrm{g}$ of wet tissue. Schiff bases $(\mathrm{SchB})$ and conjugated trienes $(\mathrm{CoT})$ were extracted by mixture heptanes/isopropanol $(3: 7, \mathrm{v} / \mathrm{v})$. The heptane layer was measured at $220 \mathrm{~nm}$ (isolated double bonds), $278 \mathrm{~nm}$ (CoT) and $400 \mathrm{~nm}(\mathrm{SchB})$. The concentrations of CoT and SchB were evaluated by the $278 / 220$ and $400 / 220$ ratios and expressed as relative units (Hyshiktuyev et al., 1996).

\section{Statistical analysis}

Statistical analyses were performed with StatSoft Statistica v 7.0. Kolmogorov-Smirnov and Lilliefors tests were used to examine the normality of the distribution of the investigated parameters. Homogeneity of variance was assessed using Levene's test. As the distribution of all data deviated from the normal range, the significance of the differences was tested by non-parametric statistics. The Mann-Whitney U and Kruskal-Wallis tests were performed to test the differences in the studied biochemical indices, depending on the dose and duration of cadmium effect. The differences were considered significant at $\mathrm{p}<0.05$. The correlation of the changes in the biochemical parameters and dose-duration effects was estimated by the Spearman's rank correlation coefficients (Hill and Lewicki, 2007). The results of the lipid peroxidation products are presented in the form of the mean values \pm the standard deviation. The results of the lipid composition are presented as the mean values \pm the standard error.

\section{Results}

\subsection{Lipid composition}

Gills

In the first experimental day at $50 \mu \mathrm{g} / \mathrm{L}$ and 100 $\mu \mathrm{g} / \mathrm{L}$ of cadmium increased, sterol content was observed, and decreased LPC content was verified in the gills of $A$. cygnea (Fig. 2, Fig. 3). Further exposure (3 days) of the mussels to $100 \mu \mathrm{g} / \mathrm{L}$ cadmium resulted in a decrease in the content of the total phospholipids and their fractions (phosphatidylinositol, phosphatidylserine, sphingomyelin, phosphatidylethanolamine, phosphatidylcholine and its lysoform). The effect of $10 \mu \mathrm{g} / \mathrm{L}$ cadmium caused a decrease in the LPC content on the third day of the experiment. In addition, on the third experimental day under all studied cadmium doses, there was a decrease in TAG content in the gills (Fig. 2).

Figures 4-6 show that on the first day of the experiment under all studied cadmium doses, the saturated fatty acid content (mainly palmitic acid, 16:0) increased, and the content of monounsaturated fatty acids (primarily 20:1 acids) and n-6 PUFAs (linoleic 18:2n-6 and arachidonic 20:4n-6 acids) decreased in the gill phospholipids. At the same time, there was a decrease in the unsaturation index of the phospholipid fatty acid composition (Fig. 7). On the first experimental day, increased contents of saturated acids (20:0 and 22:0), as well as a decreased arachidonic 20:4n-6 acid content, were observed in the gill triacylglycerols (Fig. 5, Fig. 6). In contrast to the first experimental day, on the third day, the saturated fatty acid content in gill phospholipids and triacylglycerols decreased, while the content of PUFAs, predominantly the n-6 family, increased, causing a significant increase in the unsaturation index of the phospholipids and triacylglycerol fatty acids (Fig. 4-Fig. 7).

Digestive glands

In the digestive glands of $A$. cygnea, an increase in the phospholipid proportion, mainly the dominant membrane phospholipid - phosphatidylcholine (PC), was detected on the first day in 10 and $100 \mu \mathrm{g} / \mathrm{L}$ cadmium (Fig. 2, Fig. 3). There was an increase in the content of sterols (10 and 100 $\mu \mathrm{g} / \mathrm{L}$ cadmium) and triacylglycerols $(100 \mu \mathrm{g} / \mathrm{L}$ cadmium $)$. On the first experimental day under $100 \mu \mathrm{g} / \mathrm{L}$ cadmium, a decrease in the phosphatidylserine (PS) content was observed that subsequently (on the third experiment day) significantly increased under all studied cadmium doses (10, 50 and 100 $\mu \mathrm{g} / \mathrm{L}$ ). An accumulation of triacylglycerols (TAG) in the digestive glands was also noted on the third experimental 

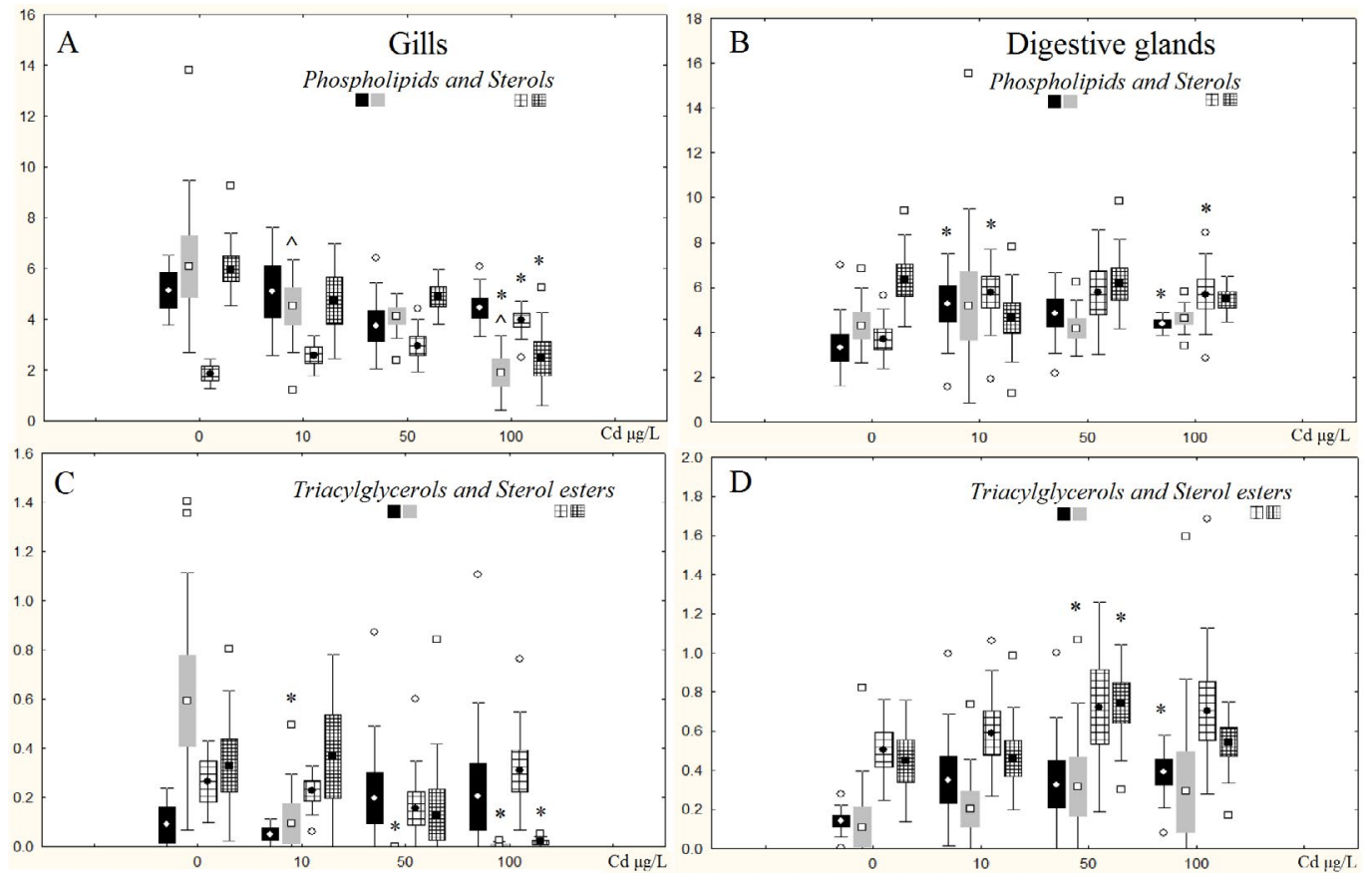

Fig. 2. Lipid classes content (\% dry weight) in gills (A and C) and digestive glands (B and D) of freshwater mussels A. cygnea under cadmium effects: black columns and columns in large cells -1 day exposure; grey columns and columns in small cells -3 days exposure. Values are means \pm standard error $(\mathrm{N}=7)$ : * - significant differences in comparison with the control (MannWhitney test, $\mathrm{P}<0.05$ ); ${ }^{\wedge}$ - significant differences compared to the cadmium concentrations (Kruskal-Wallis test, $\mathrm{P}<0.05$ ).
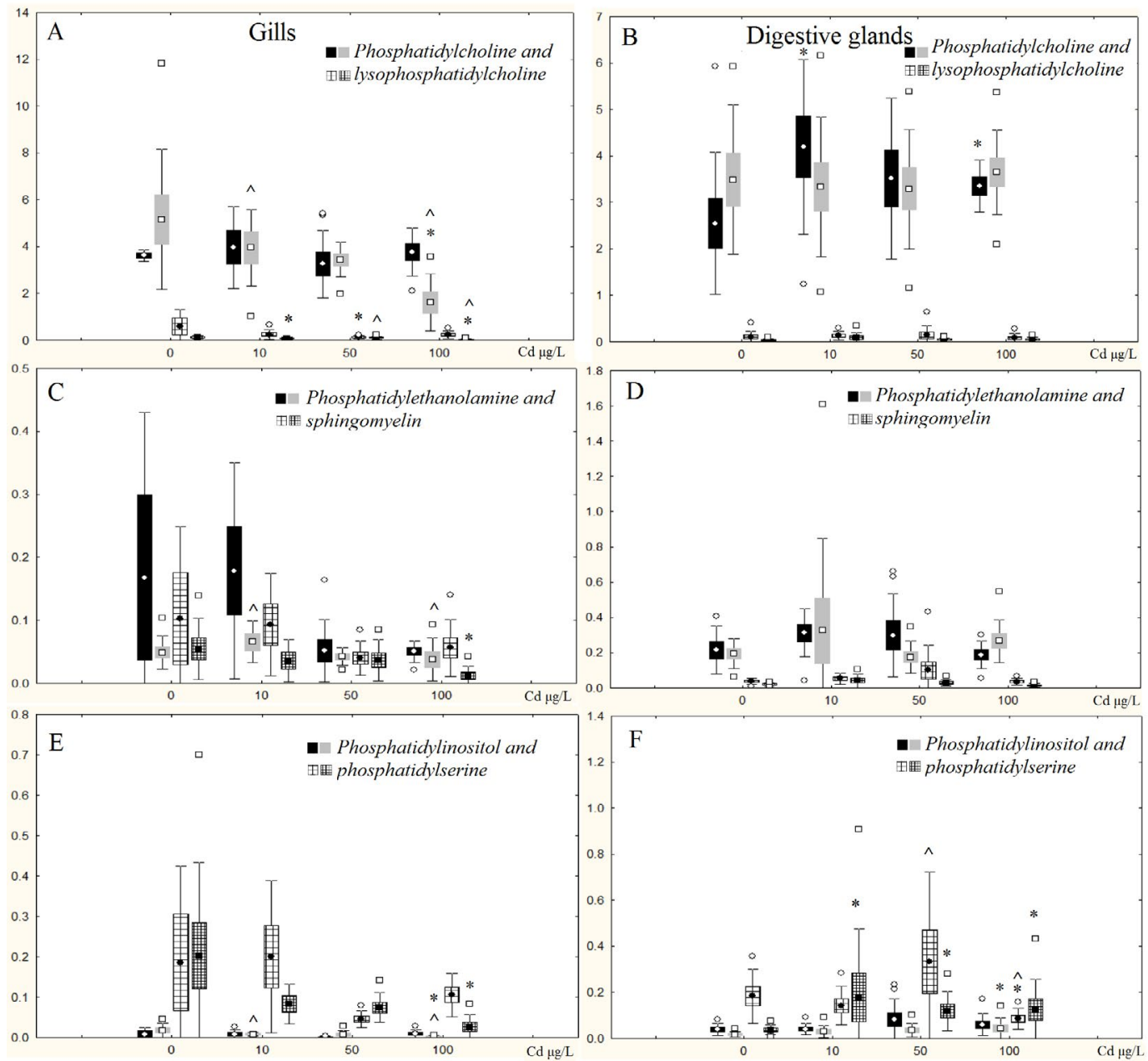

Fig. 3. Phospholipid classes content (\% dry weight) in gills (A, C and E) and digestive glands (B, D and F) of freshwater mussels A. cygnea under cadmium effects: black columns and columns in large cells - 1 day exposure; grey columns and columns in small cells -3 days exposure. Values are means \pm standard error $(\mathrm{N}=7)$ : * - significant differences in comparison with the control (Mann-Whitney test, $\mathrm{P}<0.05$ ); ^ - significant differences compared to the cadmium concentrations (Kruskal-Wallis test, $\mathrm{P}<0.05)$. 

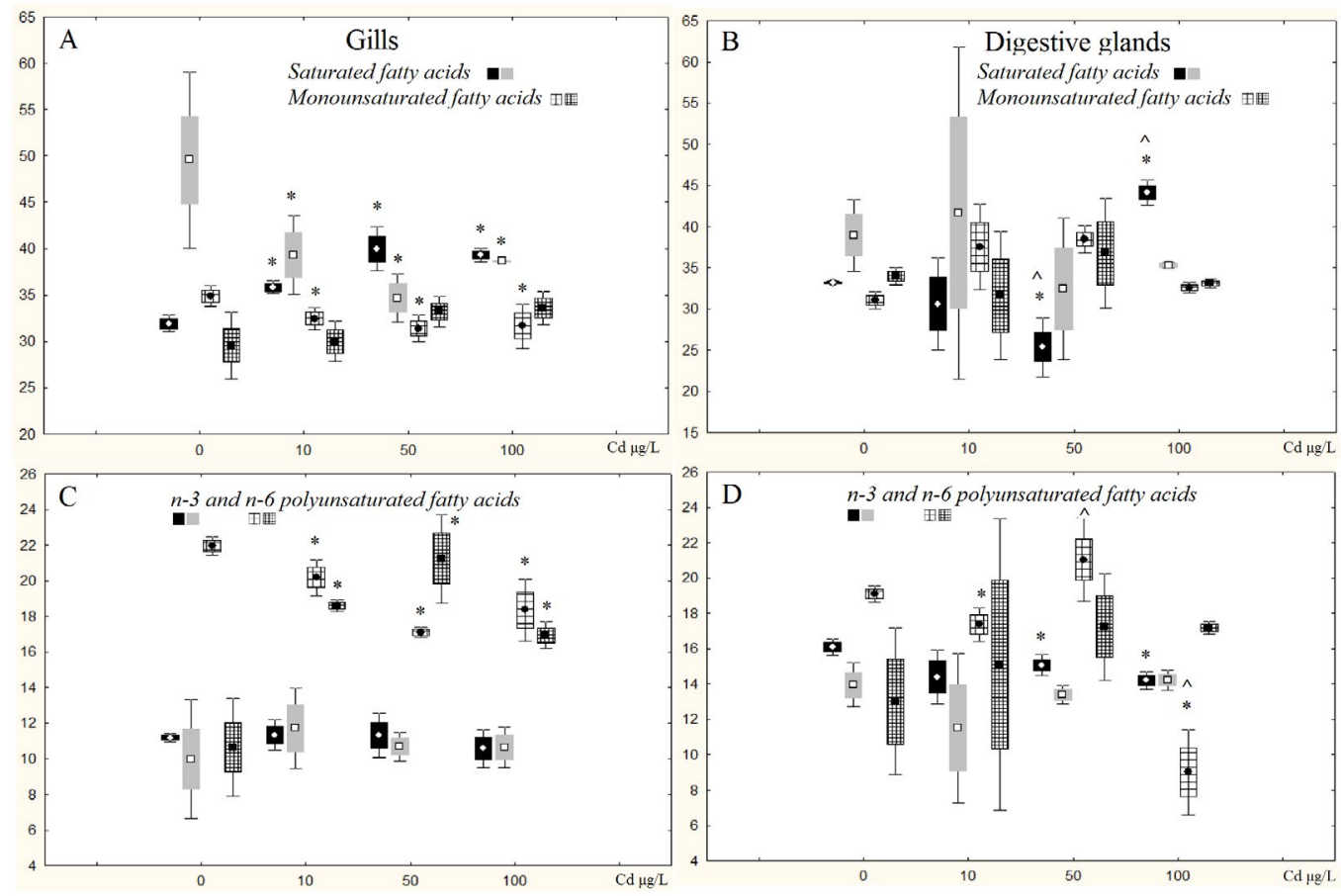

Fig. 4. Phospholipid fatty acid composition (\% sum fatty acids) of gills (A and C) and digestive glands (B and D) in freshwater mussels $A$. cygnea under cadmium effects: black columns and columns in large cells -1 day exposure; grey columns and columns in small cells -3 days exposure. Values are means \pm standard error $(\mathrm{N}=7)$ : * - significant differences in comparison with the control (Mann-Whitney test, $\mathrm{P}<0.05$ ); ${ }^{\wedge}$ - significant differences compared to the cadmium concentrations (Kruskal-Wallis test, $\mathrm{P}<0.05)$
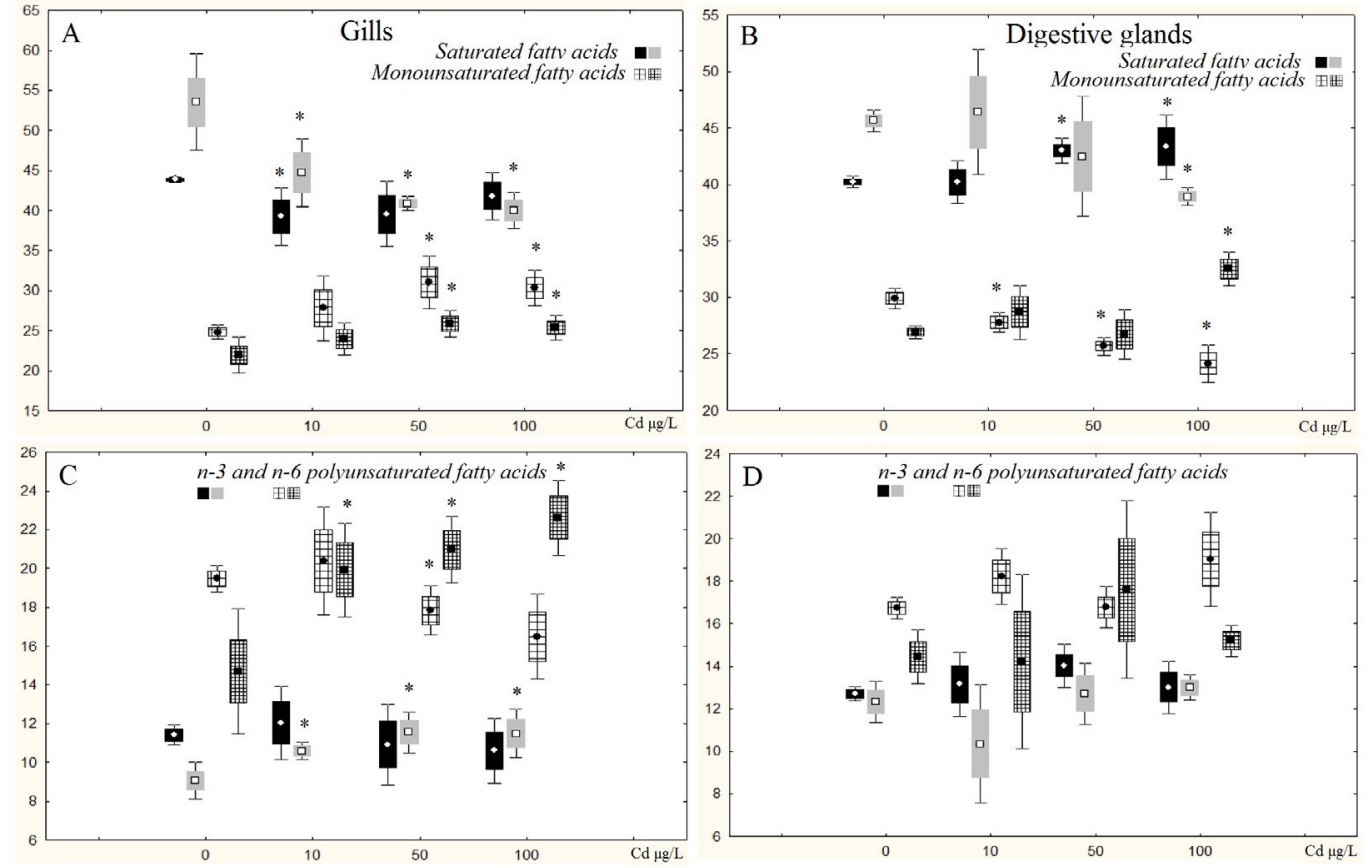

Fig. 5. Triacylglycerols fatty acid composition (\% sum fatty acids) of gills (A and C) and digestive glands (B and D) in freshwater mussels $A$. cygnea under cadmium effects: black columns and columns in large cells - 1 day exposure; grey columns and columns in small cells -3 days exposure. Values are means \pm standard error $(\mathrm{N}=7)$ : * - significant differences in comparison with the control (Mann-Whitney test, $\mathrm{P}<0.05)$; ^ - significant differences compared to the cadmium concentrations (KruskalWallis test, $\mathrm{P}<0.05)$. 

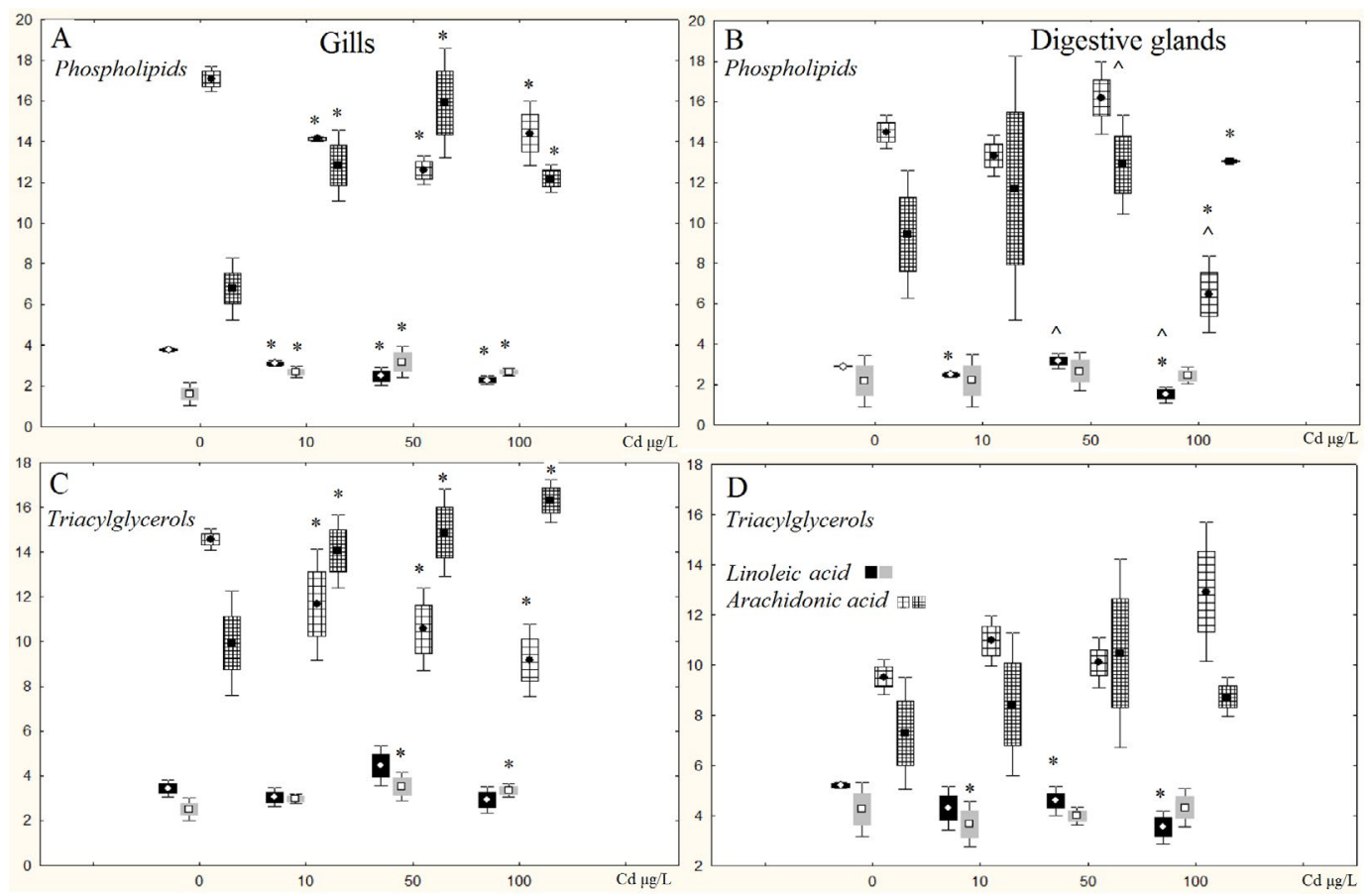

Fig. 6. Content of linoleic acid and arachidonic acid (\% sum fatty acids) in phospholipids (A and B) and triacylglycerols (C and D) of gill (A and C) and digestive glands (B and D) in freshwater mussels A. cygnea under cadmium effects: black columns and columns in large cells -1 day exposure; grey columns and columns in small cells -3 days exposure. Values are means \pm standard error $(\mathrm{N}=7)$ : $*$ - significant differences in comparison with the control (Mann-Whitney test, $\mathrm{P}<0.05){ }^{\wedge}{ }^{\wedge}-$ significant differences compared to the cadmium concentrations (Kruskal-Wallis test, $\mathrm{P}<0.05$ ).

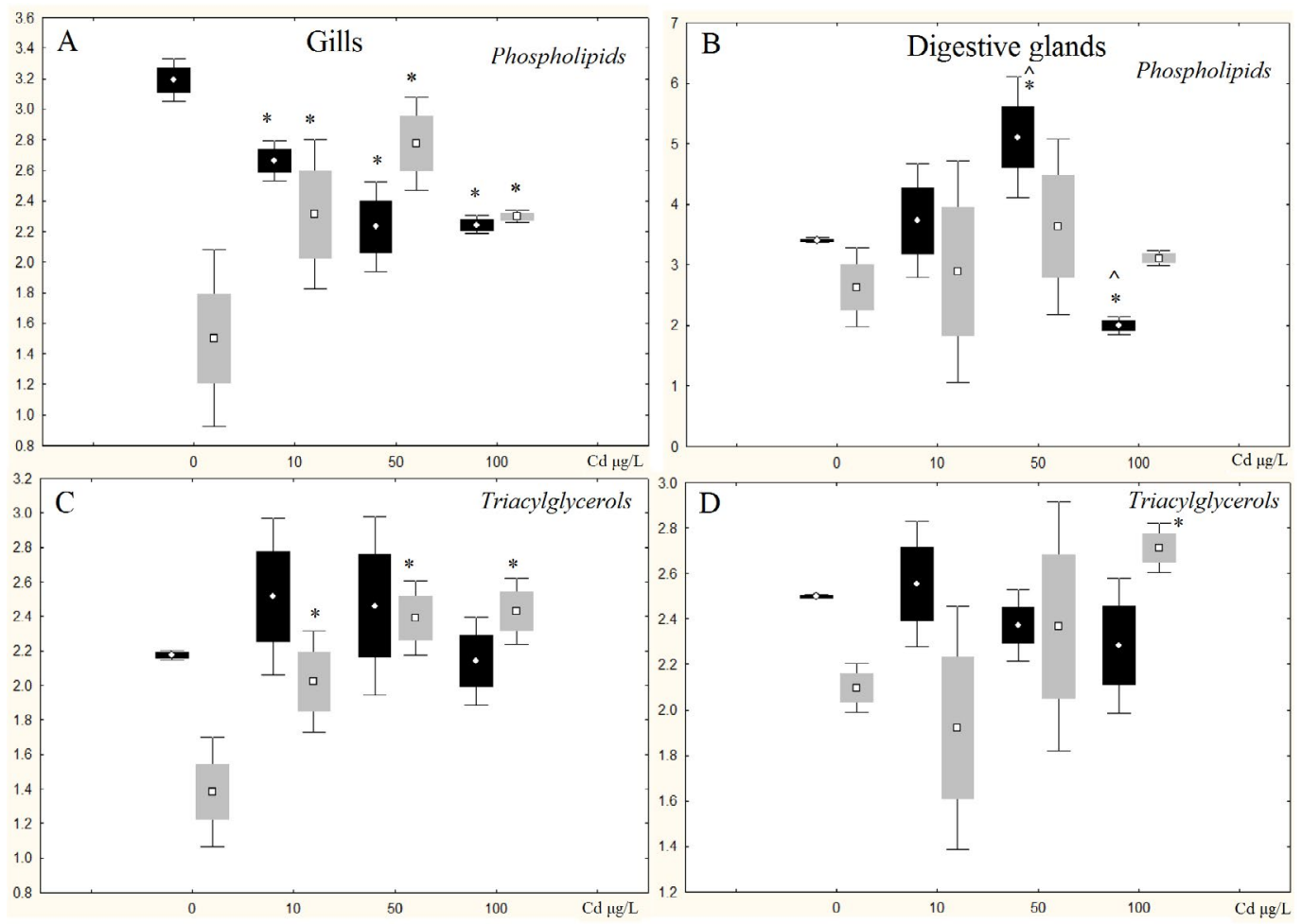

Fig. 7. Unsaturation index of phospholipids (A and B) and triacylglycerols (C and D) in gills (A and C) and digestive glands (B and D) of freshwater mussels $A$. cygnea under cadmium effects: black columns - 1 day exposure; grey columns -3 days exposure. Values are means \pm standard error $(\mathrm{N}=7)$ : * - significant differences in comparison with the control (Mann-Whitney test, $\mathrm{P}<0.05$ ); ${ }^{-}$- significant differences compared to the cadmium concentrations (Kruskal-Wallis test, $\mathrm{P}<0.05$ ). 
day (under $50 \mu \mathrm{g} / \mathrm{L}$ cadmium). On the first experimental day, changes in the fatty acid composition of the digestive gland phospholipids were determined by the cadmium concentrations (Fig. 4, Fig. 7). Thus, modifications in the fatty acid composition similar to those in the gills on the third day were observed under $50 \mu \mathrm{g} / \mathrm{L}$ cadmium (reduced saturated fatty acid content and increased unsaturation index). At the same time, under $100 \mu \mathrm{g} / \mathrm{L}$ cadmium, an increase in saturated fatty acid content and a decrease in the index of unsaturation were observed (these modifications were noted in the gills on the first experimental day). The fatty acid composition of the triacylglycerols significantly changed under 50 and 100 $\mu \mathrm{g} / \mathrm{L}$ cadmium (Fig. 5). Unlike the fatty acid composition of phospholipids, they did not depend on the cadmium concentration. On the first experimental day, there was an increase in the saturated fatty acid content (mainly palmitic acid 16:0) and a decrease in the unsaturated fatty acid content (such as MUFAs and linoleic acid). On the third experimental day, minor changes in the compositions of the digestive gland phospholipid fatty acid were noted, mainly in response to $100 \mu \mathrm{g} / \mathrm{L}$ cadmium (including an increase in arachidonic acid content); however, in triacylglycerols (under $100 \mu \mathrm{g} / \mathrm{L}$ cadmium), the level of saturated fatty acids decreased, and the unsaturation index increased (Fig. 4-Fig. 7).

\subsection{Lipid peroxidation products}

The content of the LPO products increased in contrast with that of the control in both the gills and digestive glands of A. cygnea in all cadmium-treated groups of mussels throughout the exposure period (Table 1, Table 2).

Gills

On the first experimental day, a significant increase in the CoD content of the gills of the mussels from all experimental aquariums was observed (Table 1). Unlike that in the digestive glands, the MDA content in the gills was lower, and the CoT and SchB distributions were equal. On the third experimental day, the content of the LPO products in the gills decreased slightly, except for mussels under 100 $\mu \mathrm{g} / \mathrm{L}$ cadmium, which contained a higher level of MDA, CoT, and SchB (Table 1).

Digestive glands

On the first experimental day, an increase in the contents of $\mathrm{CoD}$ and MDA in the digestive glands was observed under 10 and $50 \mu \mathrm{g} / \mathrm{L}$ cadmium (Table 2). Under $100 \mu \mathrm{g} / \mathrm{L}$ cadmium, a slight increase in the contents of CoD and MDA was noted. The content of CoT increased slightly in all experimental groups of mussels. The accumulation of the end LPO product - Schiff bases - was significant under cadmium concentrations of 50 and $100 \mu \mathrm{g} / \mathrm{L}$ (Table 2). On the third experimental day, the distribution of $\mathrm{CoD}$ in the experimental groups of the mussels remained the same, but the differences became more pronounced (Table 2). In contrast, the accumulation of the secondary LPO products (MDA and CoT) and SchB were more pronounced in the mussels under $100 \mu \mathrm{g} / \mathrm{L}$ cadmium.

\section{Discussion}

\subsection{Lipid peroxidation products changes under cadmium effect}

The gills in bivalve mollusks are the primary organs exposed to environmental factors (Avery et al., 1998; Marigómez et al., 2002). They serve as the main site of metal accumulation in mussels, making gills more susceptible to the actions of toxicants (Chelomin et al., 1998; Marigómez et al., 2002). It was shown that modifications in various metabolic parameters in the gills of marine and freshwater mussels indicate their primary reaction to environmental effects (Avery et al., 1998; Fokina et al., 2013; Wadige et al., 2014). Cadmium is a highly toxic trace metal that initiates the accumulation of LPO products (Viarengo et al., 1990; Valko et al., 2005). Some of the primary LPO products are conjugated dienes (CoD) (Sevanian and Hochstein, 1985; Gutteridge and Halliwell, 1990). In the present study, we found a higher $\mathrm{CoD}$ content in the gills of $A$. cygnea compared

Table 1. Content of lipid peroxidation products in gills of freshwater mussels A. cygnea.

\begin{tabular}{|c|c|c|c|c|}
\hline $\begin{array}{c}\text { Cadmium, } \\
\mu \mathrm{g} / \mathrm{L} \\
\end{array}$ & $\begin{array}{c}\text { Conjugated dienes, } \\
\mathrm{nM} / \mathrm{g} \text { tissue }\end{array}$ & $\begin{array}{c}\text { Malondialdehyde, } \\
\text { nM/g tissue }\end{array}$ & $\begin{array}{l}\text { Conjugated } \\
\text { trienes, RU }\end{array}$ & $\begin{array}{c}\text { Schiff bases, } \\
\text { RU } \\
\end{array}$ \\
\hline \multicolumn{5}{|c|}{$24 \mathrm{~h}$} \\
\hline control & $18.44 \pm 1.85^{\mathrm{a}}$ & $4.07 \pm 0.44^{\mathrm{a}}$ & $0.23 \pm 0.01^{\mathrm{a}}$ & $0.02 \pm 0.003^{\mathrm{a}}$ \\
\hline 10 & $66.70 \pm 9.86^{* \mathrm{a}}$ & $7.77 \pm 0.37 * \mathrm{a}$ & $0.33 \pm 0.02 * b$ & $0.02 \pm 0.002^{\mathrm{b}}$ \\
\hline 50 & $74.49 \pm 6.91^{* a}$ & $10.54 \pm 0.46 * \mathrm{ab}$ & $0.50 \pm 0.01 * a$ & $0.05 \pm 0.003^{* a}$ \\
\hline 100 & $67.21 \pm 9.70^{* \mathrm{a}}$ & $6.04 \pm 0.35^{* \mathrm{~b}}$ & $0.52 \pm 0.02^{* a b}$ & $0.13 \pm 0.011^{* \mathrm{ab}}$ \\
\hline \multicolumn{5}{|c|}{$72 \mathrm{~h}$} \\
\hline control & $14.14 \pm 0.96^{\mathrm{a}}$ & $5.40 \pm 0.54^{\mathrm{a}}$ & $0.32 \pm 0.01^{\mathrm{a}}$ & $0.02 \pm 0.003^{a}$ \\
\hline 10 & $30.81 \pm 0.86^{* \mathrm{a}}$ & $9.35 \pm 0.66^{* a}$ & $0.46 \pm 0.03 * b$ & $0.03 \pm 0.005^{* b}$ \\
\hline 50 & $22.56 \pm 1.65^{*}$ & $8.51 \pm 0.32 * b$ & $0.64 \pm 0.03 * a$ & $0.08 \pm 0.006^{* a}$ \\
\hline 100 & $23.81 \pm 2.05^{\star \mathrm{a}}$ & $15.69 \pm 0.68 * a b$ & $0.80 \pm 0.02^{* a b}$ & $0.22 \pm 0.021^{* a b}$ \\
\hline
\end{tabular}

* - significant differences between control and experimental groups (Mann-Whitney test, $\mathrm{P}<0.05$ );

a-ab-b - differences between control and experimental groups (Kruskal-Wallis test, $\mathrm{P}<0.05$ );

RU - relative units 
to that in the digestive glands. In addition, an increased level of the primary LPO products was observed in the gills of the mussels on the first experimental day. It is likely due to the accumulation of cadmium in the gills, thereby inducing oxidative stress. The CoD accumulation rates in the gills and digestive glands of the mussels were significantly lower on the third experimental day in comparison with the rates at the beginning of the experiment $(r=-0.57$ and $r=-0.39$, respectively). This indicates the progress of LPO processes and the prevalence of the propagation stage on the third day of the experimental cadmium treatment. At the same time, subsequent LPO products - malondialdehyde (MDA) and conjugated trienes (CoT) - accumulated in the gills $(r=0.32$ and $r=0.43)$, as well as Shiff bases $(\mathrm{SchB})-$ in the digestive glands $(r=0.41)$. Moreover, the accumulation of MDA, CoD (only in the gills), CoT and one of the end LPO products - SchB - had a dose-dependent effect in both the gills and digestive glands; an increase in these peroxidation products was observed under elevated cadmium dose effects (Table 1, Table 2). Perhaps the combined dose- and duration-effects are crucial for developing the oxidative stress and, consequently, accumulate LPO products in the gills and digestive glands of A. cygnea.

\subsection{Lipid composition changes under cadmium effect}

There were no significant changes in the total lipid composition of the A. cygnea gills, except for increased content of sterols on the first experimental day (significant only under $100 \mu \mathrm{g} / \mathrm{L}$ cadmium). A similar effect was observed in the digestive glands of $A$. cygnea under a one-day effect of 10 and $100 \mu \mathrm{g} / \mathrm{L}$ cadmium. In marine and freshwater mussels, the dominant sterol is cholesterol, which is necessary for the regulation of membrane permeability. It is known that the consequence of LPO activation is a disruption of membrane phospholipids and enhanced non-selective permeability of membranes (Oxidative stress..., 2011). The presence of cholesterol in cell membranes changes their susceptibility to peroxidation processes, likely by both intercepting some of the radicals and affecting the internal structure of the membrane through interaction with phospholipid fatty acids (Repetto et al., 2012). In the gills, there was a decrease in the sterol ester content, which probably replenishes the cholesterol reserves under a prolonged (three-day) cadmium effect. Previously, we showed a significant decrease in the cholesterol and phosphatidylcholine content in the digestive glands of the marine mussels, Mytilus edulis, on the first day of the cadmium effect, indicating destructive changes in the membranes (Fokina et al., 2013). Probably, in the freshwater mussels, A. cygnea, elevated cholesterol content maintains membrane integrity under the toxic effects of cadmium, except for three-day $100 \mu \mathrm{g} / \mathrm{L}$ cadmium effects. In this case, there was a significant decrease in phospholipids and their fractions. It is assumed that a significant accumulation of LPO products (such as $\mathrm{CoD}, \mathrm{MDA}, \mathrm{CoT}$, and $\mathrm{SchB}$ ) in the gills on the third day under $100 \mu \mathrm{g} / \mathrm{L}$ cadmium treatment, as well as a reduction in phospholipid content (PC, PE and LPC as predominant fractions and PI, PS and SM as minor fractions), indicates destructive changes in gill membranes. Along with an increase in the sterol content in the digestive glands, there was an increase in the contents of PC (on the first day) and PS (on the third day). The increased content of the dominant membrane phospholipid - $\mathrm{PC}$ - in the digestive glands caused by one-day 10 and $100 \mu \mathrm{g} / \mathrm{L}$ cadmium treatment presumably reflects a compensatory reaction in lipid metabolism on metal-induced oxidative stress. Significant increases in triacylglycerol (TAG) and phosphatidylserine (PS) content in the digestive glands of $A$. cygnea under cadmium effects can serve as a nonspecific biomarker reflecting the toxic effects of pollutants on bivalves. It is known that the accumulation of neutral lipids (including TAG) in the digestive glands of mussels is caused by an increase in the number of lysosomes and/or autophagosomes that supply autophagy processes (Moore et al., 2007; Koukouzika and Dimitriadis, 2008). Similar stress-inducible changes in TAG content were

Table 2. Content of lipid peroxidation products in digestive glands of freshwater mussels $A$. cygnea

\begin{tabular}{|l|c|c|c|c|}
\hline $\begin{array}{c}\text { Cadmium, } \\
\mu \mathrm{g} / \mathrm{L}\end{array}$ & $\begin{array}{c}\text { Conjugated dienes, } \\
\mathbf{n M} / \mathrm{g} \text { tissue }\end{array}$ & $\begin{array}{c}\text { Malondialdehyde, } \\
\mathbf{n M} / \mathrm{g} \text { tissue }\end{array}$ & $\begin{array}{c}\text { Conjugated } \\
\text { trienes, RU }\end{array}$ & $\begin{array}{c}\text { Schiff bases, } \\
\text { RU }\end{array}$ \\
\hline \multicolumn{5}{|c|}{$24 \mathrm{~h}$} \\
\hline control & $24.95 \pm 1.68^{\mathrm{a}}$ & $4.84 \pm 0.37^{\mathrm{a}}$ & $0.15 \pm 0.01^{\mathrm{a}}$ & $0.02 \pm 0.002^{\mathrm{a}}$ \\
10 & $68.54 \pm 9.43^{* \mathrm{a}}$ & $12.41 \pm 0.72^{* \mathrm{ab}}$ & $0.23 \pm 0.01^{*}$ & $0.02 \pm 0.003^{\mathrm{b}}$ \\
50 & $59.31 \pm 8.41^{* \mathrm{a}}$ & $10.79 \pm 0.81^{* \mathrm{a}}$ & $0.28 \pm 0.01^{* \mathrm{a}}$ & $0.06 \pm 0.005^{* \mathrm{a}}$ \\
100 & $46.16 \pm 1.97^{*}$ & $7.29 \pm 0.67^{* \mathrm{~b}}$ & $0.26 \pm 0.02^{* \mathrm{a}}$ & $0.16 \pm 0.005^{* a \mathrm{ab}}$ \\
\hline & & $72 \mathrm{~h}$ & \\
\hline control & $16.04 \pm 1.10^{\mathrm{a}}$ & $5.35 \pm 0.47^{\mathrm{a}}$ & $0.15 \pm 0.01^{\mathrm{a}}$ & $0.02 \pm 0.003^{\mathrm{a}}$ \\
10 & $65.83 \pm 2.89^{* \mathrm{ab}}$ & $9.46 \pm 0.71^{* \mathrm{a}}$ & $0.24 \pm 0.01^{* \mathrm{a}}$ & $0.10 \pm 0.012^{* \mathrm{~b}}$ \\
50 & $20.41 \pm 1.33^{* \mathrm{~b}}$ & $6.17 \pm 0.62^{\mathrm{b}}$ & $0.22 \pm 0.01^{* \mathrm{~b}}$ & $0.14 \pm 0.008^{* \mathrm{a}}$ \\
100 & $34.72 \pm 3.59^{* \mathrm{a}}$ & $13.46 \pm 0.78^{* \mathrm{ab}}$ & $0.38 \pm 0.02^{* \mathrm{ab}}$ & $0.28 \pm 0.021^{* a \mathrm{~b}}$ \\
\hline
\end{tabular}

* - significant differences between control and experimental groups (Mann-Whitney test, $\mathrm{P}<0.05$ );

a-ab-b - differences between control and experimental groups (Kruskal-Wallis test, $\mathrm{P}<0.05$ );

$\mathrm{RU}$ - relative units. 
observed in marine mussels under the impacts of pollutants (Koukouzika and Dimitriadis, 2008; Fokina et al., 2013). Additionally, the accumulation of PS in response to the toxic effects of cadmium and copper was noted in the marine mussels, Mytilus edulis (Fokina et al., 2013). Given the important role of PS in the activity regulation of membranebound enzymes (especially $\mathrm{Na}^{+} / \mathrm{K}^{+}$-ATPase), as well as TAG serving as a source of metabolic energy, we may use TAG and PS content as universal biomarkers whose changes reflect the toxic impact of pollutants for both marine and freshwater mollusks.

\subsection{Fatty acid composition of freshwater mussels}

The fatty acid composition of the gills and digestive glands of $A$. cygnea is influenced by the benthic habitat (Napolitano, 1999; Kelly and Scheibling, 2012), which contains freshwater organic matter derived from various autochthonous and allochthonous sources, including algae, vascular plants, and decaying plant and animal materials. The lipids of these organic materials contain long-chain saturated fatty acids and monounsaturated fatty acids (Napolitano, 1999). The predominant fatty acids of the phospholipids and triacylglycerols in the gills and digestive glands of $A$. cygnea were saturated fatty acids $(33-41 \%$ of the sum of fatty acids), especially palmitic 16:0 acid, stearic 18:0 acid and lignoceric 24:0 acid. Unsaturated fatty acids were dominated by monounsaturated fatty acids $(27-32 \%$ of sum of fatty acids), mainly 20:1 isomers representing 11-19\% of sum of fatty acids, as well as n-6 polyunsaturated fatty acids (18-21 $\%$ of sum of fatty acids), primarily due to linoleic $18: 2 \mathrm{n}-6$ and arachidonic 20:4n-6 acids (3.1-5.0 and 10-14 \% sum of fatty acids, respectively). The content of n-3 PUFAs was significantly lower than that of n-6 PUFAs and constituted 10 $-15 \%$ of the sum of fatty acids. Eicosapentaenoic 20:5n-3 and docosahexaenoic 22:6n-3 acids were 1.6 - 4.5 and $0.9-2.4 \%$ of the sum of fatty acids, respectively. The enlarged content of $18: 2 n-6$ and 20:4n- 6 acids in the lipids of freshwater animals is described in detail in comparative studies of marine and freshwater organism fatty acid compositions (Napolitano, 1999). Changes in the fatty acid composition of A. cygnea under cadmium experimental effects reflect the features of the fatty acid composition in freshwater mussels. It is known that the predominant polyunsaturated fatty acids in the lipids of marine mussels (including Mytilus edulis) are n-3 PUFAs (mainly eicosapentaenoic 20:5n-3 and docosahexaenoic 22:6n-3 acids) (Fokina et al., 2013; Fokina et al., 2018). The fatty acid composition of $A$. cygnea was characterized by the dominance of n-6 PUFAs and monounsaturated 20:1 fatty acids. Therefore, the main target for cadmium-induced oxidation processes was polyunsaturated fatty acids with 3 or more double bonds, especially arachidonic 20:4n-6 acid (unlike 20:5n-3 and 22:6n-3 in marine mussels as it was described in Fokina et al. (2013) and Merad et al. (2017).

\subsection{Fatty acid composition changes under cadmium effect}

On the first experimental day of cadmium treatment, a significant decrease in the proportions of the phospholipids and triacylglycerol unsaturated fatty acids (mostly linoleic 18:2n-6 and arachidonic 20:4n-6 acids), as well as monounsaturated 20:1 acids, was noted in the gills of $A$. cygnea (Fig. 4-Fig. 7). At the same time, there was an increase in the proportion of saturated fatty acids and a decrease in the unsaturation index. Simultaneously, the increases in the contents of $\mathrm{CoD}, \mathrm{MDA}$ and CoT are oxidation products of polyunsaturated fatty acids that contain 3 or more double bounds and indicate the activation of the oxidative and destructive processes in the gill membranes. It should be noted that on the third experimental day, the proportions of the unsaturated fatty acids, mainly n-6 PUFA, were restored both in the phospholipids and triacylglycerols. Probably, in the gills (organ of primary accumulation of metals) on the third experimental day, compensatory changes in the composition of the phospholipids and triacylglycerol unsaturated fatty acids through additional PUFA synthesis provide the restoration of unsaturation level of lipids under cadmium-induced oxidative stress.

In the composition of the digestive gland phospholipid fatty acids, on the first experimental day of the exposure to 50 $\mu \mathrm{g} / \mathrm{L}$ of cadmium, modifications similar to those observed in A. cygnea gills on the third day of cadmium exposure (decrease in the proportions of saturated fatty acids and increase in unsaturation index) were observed. Most likely, there is a compensation of cadmium-induced oxidative stress through an increase in unsaturation of the lipids. At the same time, under $100 \mu \mathrm{g} / \mathrm{L}$ cadmium, the proportions of saturated fatty acids increased, and the unsaturation index decreased (these modifications were noted in the A. cygnea gills on the first day). It likely indicates the destructive oxidative processes in the digestive gland membranes caused by cadmium. Unlike phospholipid fatty acid composition, changes in the composition of triacylglycerol fatty acids were independent of cadmium concentration. On the first experimental day, there was an increase in the proportions of saturated fatty acids and a decrease in the 20:1 monounsaturated fatty acid content. On the third experimental day, there was an increase in the fatty acid unsaturation index (significant only for 100 $\mu \mathrm{g} / \mathrm{L}$ cadmium).

\section{Conclusions}

Thus, the study of the lipid peroxidation products revealed the activation of cadmium-induced oxidative processes in the gills and digestive glands of $A$. cygnea under the experimental conditions. The different degrees of LPO product accumulation in the organs of the mussels reflected the intensity of the different stages of LPO and were also determined by the concentration and duration of the cadmium effect. Changes in the lipid composition of the $A$. cygnea gills and digestive glands were determined by the target organ, concentration and duration of cadmium exposure. In the fatty acid composition of the membrane lipids (phospholipids) of the gills, a significant decrease in the unsaturation level was observed on the first experimental day of the cadmium treatment. Together with a high level of LPO products, it indicated the activation of oxidative processes. In addition, the increased cholesterol content in the gills and digestive glands of $A$. cygnea on the first experimental day apparently decreased the non-selective ion permeability of the membranes. There was a restoration in the level of unsaturation of the fatty acids both in the phospholipids and 
triacylglycerols in the gills of $A$. cygnea after prolonged cadmium exposure on the third day. Some lipid indices (in particular, phosphatidylserine and triacylglycerol content) that can be used as universal biomarkers of the toxic effects of cadmium were revealed. The increased content of these lipids in the organs of the mussels (mainly in digestive glands) caused by the effects of the cadmium ions in both marine and freshwater mussels was observed. However, the changes in the fatty acid composition of the mussels under the effects of cadmium were determined by the features in the fatty acid profiles of marine and freshwater habitants. For example, it has been shown that arachidonic 20:4n-6 acid serves as the main target for cadmium-induced oxidative processes in freshwater mussels (unlike EPA and DHA in marine ones). Thus, assessment of oxidative stress biomarkers (LPO products) and the main targets for oxidative processes (lipid and their fatty acid composition) allows the evaluation of the consequences of cadmium-induced oxidative stress on the membrane and storage lipids of mussels. Moreover, it makes it possible to identify protective biochemical mechanisms (including lipid composition) that provide the high resistance of mussels to environmental pollution.

\section{Acknowledgements}

We are deeply grateful to I.V. Sukhovskaya for help in setting up the experiment. This study was supported by federal funding for governmental-order project theme no. 0218-2019-0076 (no. AAAA-A17117031710039-3) and the Russian Foundation for Basic Research (project no. 17-04-01431_a).

\section{Compliance with ethical standards} declare.

The authors have no conflicts of interest to

\section{References}

Arduini A., Peschechera A., Dottori S. et al. 1996. High performance liquid chromatography of long-chain acylcarnitine and phospholipids in fatty acid turnover studies. Journal of Lipid Research 37: 684-689.

Avery E.L., Dunstan R.H., Nell J.A. 1998. The use of lipid metabolic profiling to assess the biological impact of marine sewage pollution. Archives of Environmental Contamination and Toxicology 35: 229-235. DOI: 10.1007/s002449900371

Bird R.P., Draper H.H. 1984. Comparative studies on different methods of malondialdehyde determination. Methods in Enzymology 90: 105-110.

Chelomin V.P., Belcheva N.N., Zakhartsev M.V. 1998. Biochemical mechanisms of adaptation to cadmium and copper ions in the mussel Mytilus trossulus. Russian Journal of Marine Biology 24: 330-336.

Engelbrecht F.M., Mari F., Anderson J.T. 1974. Cholesterol determination in serum: a rapid direction method. South African Medical Journal 48: 250-256.

Fokina N.N., Ruokolainen T.R., Nemova N.N. 2018. The effect of intertidal habitat on seasonal lipid composition changes in blue mussels, Mytilus edulis L., from the White Sea. Polar Record 54: 133-151. DOI: 10.1017/ S0032247418000293

Fokina N.N., Ruokolainen T.R., Nemova N.N. et al. 2013. Changes of blue mussels Mytilus edulis L. lipid composition under cadmium and copper toxic effect. Biological Trace Element Research 154: 217-225. DOI: 10.1007/s12011-0139727-3Folch J., Lees M., Stanley J. 1957. A simple method for isolation and purification of total lipids from animal tissues. The Journal of Biological Chemistry 226: 497-509.

Gavrilov V.B., Gavrilova A.R., Mazhul L.M. 1987. Analysis of methods for the determination of lipid peroxidation products in blood serum by the test with thiobarbituric acid. Voprosy Meditsinskoy Khimii [Questions of Medical Chemistry] 1: 118-121. (In Russian)

Geret F., Serafim A., Barreira L. et al. 2002. Effect of cadmium on antioxidant enzyme activities and lipid peroxidation in the gills of the clam Ruditapes decussatus. Biomarkers 7: 242-256. DOI: 10.1080/13547500210125040

Gladyshev M.I., Anishchenko O.V., Sushchnik N.N. et al. 2012. Influence of anthropogenic pollution on content of essential polyunsaturated fatty acids in links of food chain of river ecosystem. Contemporary Problems of Ecology 5: 376-385. DOI: 10.1134/S1995425512040051

Gutteridge J.M., Halliwell B. 1990. The measurement and mechanism of lipid peroxidation in biological systems. Trends in Biochemical Sciences 15: 129-135. DOI: 10.1016/0968-0004(90)90206-Q

Hill T., Lewicki P. 2007. STATISTICS Methods and Applications. A comprehensive reference for science, industry, and data mining: StatSofr Inc.

Hyshiktuyev B.S., Hyshiktuyeva N.A., Ivanov V.N. 1996. Methods of measuring of lipid peroxidation products in exhaled air condensate and their clinical significance. Klinicheskaia Laboratornaia Diagnostika [Clinical Laboratory Diagnostics] 3: 13-15. (in Russian)

Kelly J.R., Scheibling R.E. 2012. Fatty acids as dietary tracers in benthic food webs. Marine Ecology Progress Series 446: 1-22. DOI: 10.3354/meps09559

Koukouzika N., Dimitriadis V.K. 2008. Aspects of the usefulness of five marine pollution biomarkers, with emphasis on MN and lipid content. Marine Pollution Bulletin 56: 941-949. DOI: 10.1016/j.marpolbul.2008.01.043

Manly R., George W.O. 1977. The occurrence of some heavy metals in populations of the freshwater mussel Anodonta anatina (L.) from the River Thames. Environmental Pollution 14: 139-154. DOI: 10.1016/0013-9327(77)90106-9

Marigómez I., Soto M., Cajaraville M.P. et al. 2002. Cellular and subcellular distribution of metals in molluscs. Microscopy Research and Technique 56: 358-392. DOI: 10.1002/jemt.10040

Méndez-Armenta M., Ríos C. 2007. Cadmium neurotoxicity. Environmental Toxicology and Pharmacology 23: 350-358. DOI: 10.1016/j.etap.2006.11.009

Merad I., Bellenger S., Hichami A. et al. 2017. Effect of cadmium exposure on essential omega-3 fatty acids in the edible bivalve Donax trunculus. Environmental Science and Pollution Research 25: 18242-18250. DOI: 10.1007/ s11356-017-9031-4

Moore M.N., Viarengo A., Donkin P. et al. 2007. Autophagic and lysosomal reactions to stress in the hepatopancreas of blue mussels. Aquatic Toxicology 84: 80-91. DOI: 10.1016/j. aquatox.2007.06.007

Napolitano G.E. 1999. Fatty acids as trophic and chemical markers in freshwater ecosystems. In: Lipids in freshwater ecosystems. New York, pp. 21-44.

Ohkawa H., Ohishi N., Yagi K. 1979. Assay for lipid peroxides in animal tissues by thiobarbituric acid reaction. Analytical Biochemistry 95: 351-358. DOI: 10.1016/0003-2697(79)90738-3

Oxidative stress in aquatic ecosystems. 2011. In: Abele D., Vazquez-Medina J.P., Zenteno-Savin T. (Eds.). London: John Wiley \& Sons. 
Perceval O., Pinel-Alloul B., Méthot G. et al. 2002. Cadmium accumulation and metallothionein synthesis in freshwater bivalves (Pyganodon grandis): relative influence of the metal exposure gradient versus limnological variability. Environmental Pollution 118: 5-17. DOI: 10.1016/ S0269-7491(01)00282-2

Perrat E., Couzinet-Mossion A., Tankoua O.F. et al. 2013. Variation of content of lipid classes, sterols and fatty acids in gonads and digestive glands of Scrobicularia plana in relation to environment pollution levels. Ecotoxicology and Environmental Safety 90: 112-120. DOI: 10.1016/j. ecoenv.2012.12.019

Ravera O. 1984. Cadmium in freshwater ecosystems. Experientia 40: 1-14. DOI: 10.1007/BF01959096

Regoli F., Nigro M., Orlando E. 1998. Lysosomal and antioxidant responses to metals in the Antarctic scallop Adamussium colbecki. Aquatic Toxicology 40: 375-392. DOI: 10.1016/S0166-445X(97)00059-3

Repetto M., Semprine J., Boveris A. 2012. Lipid peroxidation: chemical mechanism, biological implications and analytical determination. In: Catala A. (Ed.), Lipid peroxidation. Rijeka, pp. 3-31. DOI: 10.5772/45943

Sevanian A., Hochstein P. 1985. Mechanisms and consequences of lipid peroxidation in biological systems. Annual Review of Nutrition 5: 365-390.

Sidorov V.S., Lizenko E.I., Bolgova O.M. et al. 1972. Fish lipids. 1. Analysis technique. In: Potapova O.I., Smirnov Y.A. (Eds.), Lososevyye (Salmonidae) Karelii. Petrozavodsk, pp. 150-162. (in Russian).

Slukovskii Z.I., Ilmast N.V., Sukhovskaya I.V. et al. 2017. The geochemical specifics of modern sedimentation processes on the bottom of a small lake Lamba under technogenic impact. Trudy Karel'skogo Nauchnogo Tsentra Rossiyskoy Akademii Nauk [Transactions of Karelian Research Centre of Russian Academy of Science] 10: 45-63. DOI: 10.17076/lim618 (in Russian)

Suzuki R., Noguchi R., Ota T. et al. 2001. Cytotoxic effect of conjugated trienoic fatty acids on mouse tumor and human monocytic leukemia cells. Lipids 36: 477-482. DOI: 10.1007/ s11745-001-0746-0

Traverso N., Menini S., Maineri E.P. et al. 2004. Malondialdehyde, a lipoperoxidation-derived aldehyde, can bring about secondary oxidative damage to proteins. The Journals of Gerontology Series A: Biological Sciences and Medical Sciences 59: 890-895. DOI: 10.1093/gerona/59.9.B890

Valko M.H.C.M., Morris H., Cronin M.T.D. 2005. Metals, toxicity and oxidative stress. Current Medicinal Chemistry 12: 1161-1208. DOI: 10.2174/0929867053764635

Viarengo A., Canesi L., Pertica M. et al. 1990. Heavy metal effects on lipid peroxidation in the tissues of Mytilus galloprovincialis lam. Comparative Biochemistry and Physiology Part C: Comparative Pharmacology 97: 37-42. DOI: 10.1016/0742-8413(90)90168-9

Wadige C.P.M., Maher W.A., Taylor A.M. et al. 2014. Exposuredose-response relationships of the freshwater bivalve Hyridella australis to cadmium spiked sediments. Aquatic Toxicology 152: 361-371. DOI: 10.1016/j.aquatox.2014.04.016

Waller R.L., Recknagel R.O. 1977. Determination of lipid conjugated dienes with tetracyano - ethylene-14C: Significance for study of the pathology of lipid peroxidation. Lipids 12: 914-921. DOI: $10.1007 / \mathrm{BF} 02533311$

Xia L., Chen S., Dahms H.U. et al. 2016. Cadmium induced oxidative damage and apoptosis in the hepatopancreas of Meretrix meretrix. Ecotoxicology 25: 959-969. DOI: 10.1007/ s10646-016-1653-7 